\title{
JNNP
}

\section{Stroke thrombolysis in England, Wales and Northern Ireland: how much do we do and how much do we need?}

A G Rudd, A Hoffman, R Grant, et al.

J Neurol Neurosurg Psychiatry published online June 25, 2010

doi: 10.1136/jnnp.2009.203174

Updated information and services can be found at:

http://jnnp.bmj.com/content/early/2010/06/25/jnnp.2009.203174.full.html

These include:

References This article cites 21 articles, 13 of which can be accessed free at: http://jnnp.bmj.com/content/early/2010/06/25/jnnp.2009.203174.full.html\#ref-list-1

$\mathbf{P}<\mathbf{P} \quad$ Published online June 25, 2010 in advance of the print journal.

Email alerting Receive free email alerts when new articles cite this article. Sign up in the service box at the top right corner of the online article.

Notes

Advance online articles have been peer reviewed and accepted for publication but have not yet appeared in the paper journal (edited, typeset versions may be posted when available prior to final publication). Advance online articles are citable and establish publication priority; they are indexed by PubMed from initial publication. Citations to Advance online articles must include the digital object identifier (DOIs) and date of initial publication.

To order reprints of this article go to:

http:/jnnnp.bmj.com/cgi/reprintform

To subscribe to Journal of Neurology, Neurosurgery \& Psychiatry go to:

http://jnnp.bmj.com/subscriptions 


\title{
Stroke thrombolysis in England, Wales and Northern Ireland: how much do we do and how much do we need?
}

\author{
A G Rudd, A Hoffman, R Grant, J T Campbell, D Lowe, On behalf of the \\ Intercollegiate Working Party for Stroke
}

Clinical Standards Department, Royal College of Physicians, London, UK

\section{Correspondence to}

Dr A Rudd, Stroke Unit, St

Thomas Hospital, London SE1

7EH, UK;

anthony.rudd@kcl.ac.uk

Received 14 December 2009

Revised 11 April 2010

Accepted 13 April 2010

\begin{abstract}
Background Data are limited on the proportion of stroke patients nationally appropriate for thrombolysis either within the $3 \mathrm{~h}$ time window or the recently tested $4.5 \mathrm{~h}$. This information is important for the redesign of services. Methods Data on case mix, eligibility for thrombolysis, treatment and outcomes were extracted from the National Sentinel Stroke 2008 Audit dataset. This contains retrospective data on up to 60 consecutive stroke admissions from each acute hospital in England, Wales and Northern Ireland between 1 April and 30 June 2008.
\end{abstract}

Findings All relevant hospitals participated, submitting data on 11262 acute stroke patients. 2118 patients arrived within $2 \mathrm{~h}$ and 2596 within $3 \mathrm{~h}$ of the onset of symptoms and 587 people were already in hospital. Therefore, 28\% (3183) were potentially eligible for thrombolysis based on a $3 \mathrm{~h}$ time criterion. Of these, 1914 were under 80 years and 2632 had infarction with $14 \%$ (1605) meeting all three National Institute of Neurological Disorders and Stroke study criteria and so being potentially eligible for thrombolysis. If the time window is increased to $4.5 \mathrm{~h}$ then only another $2 \%$ became eligible. If the age limit was removed for treatment, the percentage potentially appropriate for tissue plasminogen activator increased to $23 \%$ within $3 \mathrm{~h}$ and $26 \%$ within $4.5 \mathrm{~h}$. Overall, $1.4 \%$ (160) of patients were thrombolysed.

Interpretation Thrombolysis rates are currently low in the UK. $14 \%$ of patients in this sample were potentially suitable for thrombolysis using the $3 \mathrm{~h}$ time window. This would only increase marginally if thrombolysis was extended to include those up to $4.5 \mathrm{~h}$. The greatest impact on increasing the proportion of patients suitable for thrombolysis would be to increase the number of patients presenting early and by demonstrating that the treatment is safe and effective in patients over 80 years of age.

\section{INTRODUCTION}

The evidence showing that thrombolysis is beneficial within $3 \mathrm{~h}^{1}$ and possibly $4.5 \mathrm{~h}^{2}$ of the onset of ischaemic stroke symptoms is strong, with significant reduction in long term disability. The earlier treatment is given, the greater the chance of a good outcome. Thrombolysis for stroke is however a treatment with a high risk of adverse effects, particularly intracerebral haemorrhage, with an $8.7 \%$ incidence of symptomatic intracranial bleeding (haemorrhage causing death or clinical deterioration). ${ }^{1}$ Data from the Safe Implementation of Thrombolysis in Stroke-Monitoring Study (SITS-MOST) register ${ }^{3}$ suggests a much lower rate of bleeding $(1.7 \%)$ but it is probable that there is selection bias in this dataset and more weight should be given to data from rigorous randomised controlled trials. Evidence from centres reporting the introduction of thrombolysis into routine clinical care has highlighted the importance of skilled clinical management in minimising the risk of complications. Cleveland, Ohio, USA, reported a $15 \%$ symptomatic haemorrhage rate in the first year of practice ${ }^{4}$ which resulted from widespread failure to adhere to inclusion and exclusion criteria for treatment. The UK has been slow to adopt thrombolysis compared with some other countries, $^{5-7}$ with less than $0.2 \%$ of patients reported to have received the treatment in the 2006 National Sentinel Audit of Stroke. ${ }^{8}$ A few centres have developed effective acute care and are thrombolysing a significant proportion of their patients. ${ }^{9}$ The Department of Health National Stroke Strategy in England ${ }^{10}$ has been published which identifies, among many other aspects of stroke care, the need to improve public awareness of stroke and the need to develop services that deliver high quality acute care, including thrombolysis, when appropriate. The National Institute for Health and Clinical Excellence (NICE) guidance was published on acute stroke care in 2008 in England, ${ }^{11}$ following on from a Technology Appraisal in 2007, ${ }^{12}$ and it recommends the use of thrombolysis.

It is important that services, currently in the process of major restructuring to deliver effective acute stroke care, know the size of the problem they will have to deal with. This study is one of the first to report national level data covering all hospitals and describing potential requirements for stroke thrombolysis. The aims of this study were:

- To use national audit data to establish the proportion of patients receiving thrombolysis and compare this to the proportion that could benefit.

- To assess the proportion of patients that might be eligible for thrombolysis if treatment was extended from $3 \mathrm{~h}$ to $4.5 \mathrm{~h}$ and if the treatment was routinely given to patients over 80 years.

- To assess the effect of the time of day of hospital admittance on the availability of thrombolysis.

- To establish whether patients receiving thrombolysis are admitted to an adequately equipped acute stroke unit. 


\section{METHODS}

The National Sentinel Audit of Stroke has been conducted biannually since 1998 with participation currently from all hospitals treating acute stroke patients in England, Wales and Northern Ireland. The audit tool uses standards based on best available evidence, ${ }^{13}$ and was developed by the Intercollegiate Stroke Working party that includes a wide range of experts from specialities involved in delivering stroke care as well as user representatives. All hospitals within England, Wales, Northern Ireland and the Channel Islands were invited to take part in the sixth round of the National Sentinel Audit of Stroke. The minimum requirements were that they had inpatient services for stroke patients and had admitted at least 20 patients with a primary diagnosis of stroke (ICD10 I61, I63 and I64) between 1 April and 30 June 2008. Details of the audit questionnaire are available at http://www.rcplondon.ac.uk/stroke. The clinical proforma was completed on up to 60 consecutive patients (median 59 per hospital), 1 April and 30 June 2008, to assess compliance with evidence based standards, to define case mix and outcome. Using a web based tool with inbuilt validation, very high levels of data completeness and internal consistency were achieved. An inter-rater reliability study was conducted on the first five patients to estimate the agreement in data as collected by a second auditor with access to the same information and this demonstrated good to excellent levels of agreement (median $\kappa=0.77$, IOR $0.67-0.86, \mathrm{n}=77$ categorical questions).

The data collected covered the whole inpatient stroke pathway but did not cover all the inclusion and exclusion criteria as defined by the National Institute of Neurological Disorders and Stroke (NINDS) study ${ }^{14}$ (ie, uncontrolled hypertension, profound premorbid dependency or current use of anticoagulants). However, data from the 2006 audit which did record premorbid disability and use of anticoagulation prior to admission suggest the number of patients excluded for reasons other than time since stroke onset (more than $3 \mathrm{~h}$ and more than $4.5 \mathrm{~h}$ ), age over 80 years and haemorrhage on brain imaging is likely to be relatively small. We did not collect the data in the 2008 audit for the number of patients admitted on anticoagulants or on Barthel prior to admission.

Data were cleaned and analysed at the Royal College of Physicians' Clinical Effectiveness and Evaluation Unit, using SPSS V.15 software. Times of admission and thrombolysis were collected to the minute but many participants rounded times to wider intervals, including the nearest hour in some cases, so we present time to thrombolysis to the nearest hour. This will have only a small impact on overall eligibility for reasons discussed below under 'Relaxing the NINDS criteria'. All data were submitted by individual hospitals without any patient identifiers. Where admission times were not known, we assumed that these patients would not have been eligible for tissue plasminogen activator (tPA). Ethics approval was not required for this audit and individual patient consent was not obtained.

\section{RESULTS}

All eligible hospitals (216) treating acute stroke patients participated in the audit and they submitted data on 11369 patients. Of these, 107 were excluded for this paper as they received rehabilitation care only. This left 215 hospitals (England $n=183$, Wales $n=18$, Northern Ireland $n=11$ and Islands $n=3$ ) and 11 262 patients. Some 47\% (5306) of patients were male, mean age 72 years, with $53 \%$ (5956) female, mean age 79 years. Motor deficits were recorded in $77 \%$ (8668), dysphasia in 39\% (4425) and dysarthria in $39 \%$ (4384). Of the 96\% (10849) receiving a brain scan, $87 \%$ (9431) had infarction on the scan and $13 \%$ (1418) haemorrhage. At some point in the first week after the stroke, $13 \%(1476 / 11262)$ of patients were recorded as being unconscious. This was higher for haemorrhagic strokes $(30 \%$, 423/1418) than infarctions (8\%, 797/9431). Seventy-eight per cent $(8495 / 10859)$ were independent in everyday activities before the stroke.

\section{Eligibility for and receipt of thrombolysis}

The date of stroke was known for $77 \%$ (8670) and was estimated by hospitals in $23 \%$ (2587); data were missing for five cases. The time of stroke during the day was known for $58 \%$ $(5031 / 8670)$ while $30 \%(1075 / 3639)$ of those with unknown times occurred during sleep. The time of stroke and the time of admission to hospital were both known for 4980, with 262 of these being inpatients at the time of onset. Stroke and admission times were subject to a certain degree of rounding, particularly to the nearest half and full hours, and to accommodate this the time elapsing between stroke and admission was rounded to the nearest hour and was computable for 4600 of the 4718 patients admitted after onset of symptoms. Of these, $46 \%$ (2118) arrived at the hospital within $2 \mathrm{~h}$ of onset, $56 \%$ (2596) within $3 \mathrm{~h}, 64 \%$ (2944) within $4 \mathrm{~h}$ and 70\% (3223) within $5 \mathrm{~h}$.

There were 587 inpatients at the time of stroke and so overall $28 \%(2596+587=3183 / 11262)$ were potentially eligible for thrombolysis based on the $3 \mathrm{~h}$ time criterion assuming that the majority of patients in a hospital bed should expect to have acute stroke recognised within $3 \mathrm{~h}$ of the onset of symptoms although some would not be eligible for reasons such as recent surgery or comorbidities. Of these, 1914 (17\%) were younger than 80 years and 2632 (23\%) had infarction. In all, 14\% (1605/ 11262) met all three criteria and were therefore potentially eligible. Only $10 \%(160 / 1605)$ of the eligible patients were thrombolysed and half (80) of these were from just 14 hospitals. Almost all hospitals (209) had at least one eligible patient and 65 of these gave thrombolysis to some eligible patients. Of the 9657 patients who were not strictly eligible under the NINDS criteria, $44(0.5 \%)$ received thrombolysis and 24 of these were aged over 80 years, 10 were admitted within $4.5 \mathrm{~h}$ and none was an inpatient at the time of stroke.

\section{Hospital variation in eligibility for and receipt of thrombolysis}

The percentage of patients available for thrombolysis within $3 \mathrm{~h}$ of symptoms varied between hospitals (median 28\%, IOR $21-35 \%)$. The percentage of patients meeting all three NINDS criteria varied (median 13\%, IOR 9-18\%). Only 31\% (65/209) of hospitals with eligible patients used thrombolysis, and these 65 hospitals treated a median of $20 \%$ (IOR 14-33\%) of eligible patients. Hospitals with larger numbers of eligible patients were more likely to treat (Spearman $\mathrm{r}=0.28, \mathrm{p}<0.001$ ) (table 1 ).

\section{Relaxing the NINDS criteria}

Overall, 32\% (3558) were admitted within a $4.5 \mathrm{~h}$ window and $35 \%$ (3960) within 6 h, including inpatients at onset. Removing the age restriction increased potential eligibility for patients

Table 1 Receipt of thrombolysis according to the number of eligible patients

\begin{tabular}{lllll}
\hline & $\begin{array}{l}\mathbf{4 1} \text { hospitals } \\
\text { with }>10 \\
\text { eligible } \\
\text { patients }\end{array}$ & $\begin{array}{l}\mathbf{6 0} \text { hospitals } \\
\text { with 8-10 } \\
\text { eligible } \\
\text { patients }\end{array}$ & $\begin{array}{l}\mathbf{6 3} \text { hospitals } \\
\text { with } \mathbf{5 - 7} \\
\text { eligible } \\
\text { patients }\end{array}$ & $\begin{array}{l}\mathbf{4 5} \text { hospitals } \\
\text { with 1-4 } \\
\text { eligible } \\
\text { patients }\end{array}$ \\
\hline $\begin{array}{l}\%(\mathrm{n}) \text { patients } \\
\text { treated }\end{array}$ & $16 \%(90 / 577)$ & $7 \%(39 / 530)$ & $6 \%(23 / 366)$ & $6 \%(8 / 132)$ \\
\hline
\end{tabular}


with infarction from $14 \%$ to $23 \%$ (2632) for the $3 \mathrm{~h}$ window, to $26 \%$ (2951) within $4.5 \mathrm{~h}$ and to $29 \%$ (3294) within $6 \mathrm{~h}$. Maintaining the age restriction but extending the time window to $4.5 \mathrm{~h}$ increased eligibility from $14 \%$ to $16 \%$ (1811).

\section{Time of admission to hospital}

Time of admission was known for 10538 (94\%) stroke patients who were admitted to hospital. Two-thirds of these (67\% (7070/ 10538)) were admitted between 08:00 and 18:00 h, of whom 13\% (903) were eligible under NINDS, while 33\% (3468/10538) were admitted between 19:00 and 07:00 h of whom 13\% (446) were eligible. Significantly more eligible patients received thrombolysis between 08:00 and 18:00 h than outside these hours (14\% (126/ $903)$ vs $5 \%(24 / 446) ; p<0.001)$. Of 587 inpatients at the time of stroke, $44 \%$ (256) were eligible, of whom 3.9\% (10) were treated. Figure 1 shows the variation in time of day for the 10538 admitted patients, and within this the variation in numbers eligible for and treated by thrombolysis can be seen.

\section{Gender}

Whereas 18\% (937/5306) of men were eligible using NINDS criteria, only $11 \%(668 / 5956)$ of women were eligible. Female patients were however older than male patients and if the NINDS age restriction is relaxed, then $24 \%(1277 / 5306)$ of men would be eligible and $23 \%(1355 / 5956)$ of women. Rates overall for men and women entering hospital within $3 \mathrm{~h}$ of onset, including existing inpatients, were similar at 29\% (1525/5306) and 28\% (1658/5956), respectively, and rates for infarction on brain scanning were also very similar at 87\% (4914/5667) for women and $87 \%(4517 / 5182)$ for men. A lower proportion of eligible women $(9 \%, 61 / 668)$ received thrombolysis than eligible men $(11 \%$, $99 / 937)$ but this was not statistically significant $(p=0.35)$.

\section{Case mix and admission characteristics}

Variables applying at onset or at admission or soon after are summarised in table 2 . Eligibility rates did not display much

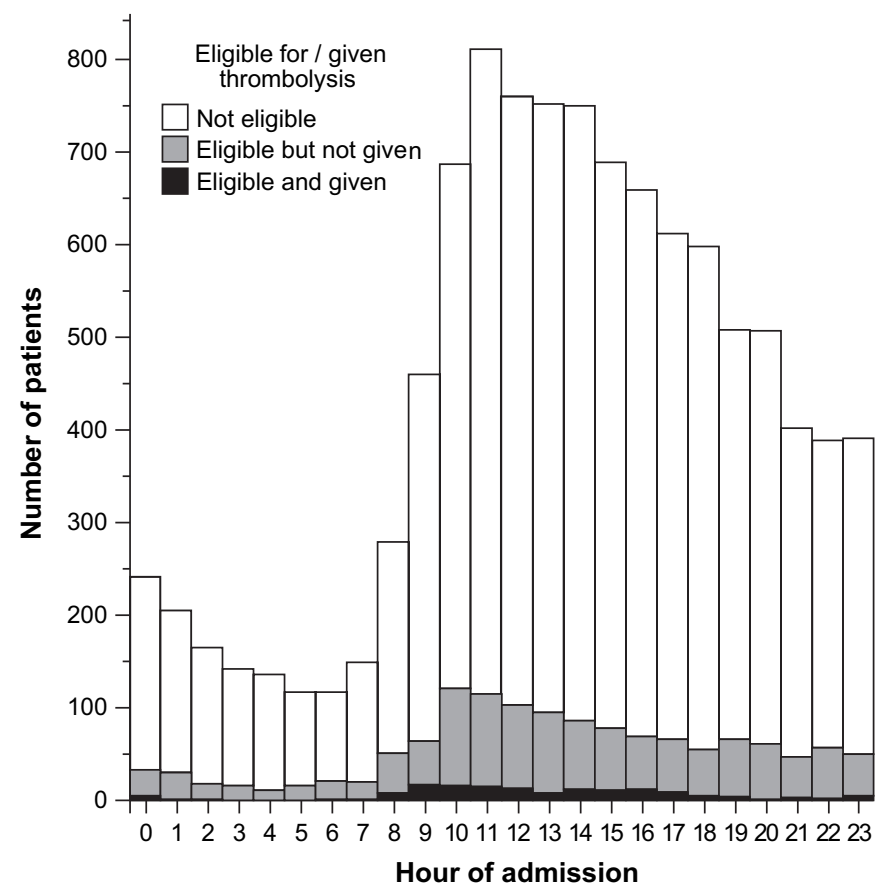

Figure 1 Time of day patients admitted to hospital for whole cohort divided by eligibility for, and provision of, thrombolysis $(n=10538$ admitted). variation between patient subgroups apart from existing inpatients (44\%). Eligibility variation overall is explainable by the associations between these variables and the factors (admission $<3 \mathrm{~h}$, brain scan infarction, age 80 years or under) determining the NINDS criteria. The overall treatment rate for eligible patients was $10 \%$ and there was notable variation (table 1) in relation to age (under 65 s $13 \%$ vs $65-80$ s $9 \%$ ), in being capable of independent living before the stroke (yes $11 \%$ vs no $4 \%$ ), prior comorbidities (none $18 \%$ vs one or more $8 \%$ ), use of lipid lowering treatment prior to stroke (yes $8 \%$, no $12 \%$ ), having an ambulance patient record on file and Face, Arm, Speech Test (FAST) available (yes $21 \%$ vs no $7 \%$ ), being admitted during working hours (08:00-18:00 h $14 \%$ vs 19:00-07:00 5\% vs existing inpatient 4\%) and having dysphasia, dysarthria and motor deficits during the first $24 \mathrm{~h}$ (none $1 \%$ vs one $4 \%$ vs two/three 14\%). The worst level of consciousness at the time of maximum severity in the first week after stroke did not predict thrombolysis use nor did current smoking or alcohol excess.

\section{Acute stroke units and ambulance records}

Within $4 \mathrm{~h}$ of admission to hospital, 69\% (111/160) of eligible and thrombolysed patients were admitted to an acute or combined stroke unit. This compares with 19\% (275/1445) of those eligible but not thrombolysed. Five characteristics were used in the audit to identify quality of care in acute or combined stroke units. These were continuous physiological monitoring (ECG, oximetry, blood pressure), access to scanning within $3 \mathrm{~h}$ of admission, direct admission from the accident and emergency department, specialist ward rounds at least five times a week and presence of acute stroke protocols/guidelines. Some 111 of 191 sites with acute or combined stroke units possessed only four or fewer of these characteristics and 17 of these 111 carried out thrombolysis on eligible patients in this audit. These 17 sites had 145 eligible patients and thrombolysed 21\% (31) of them. Therefore, $19 \%$ (ie, 31/160) of all eligible and thrombolysed patients were thrombolysed in centres without fully equipped acute specialist stroke beds.

\section{Outcomes}

Inpatient mortality was $12 \%$ (19/160) for eligible treated patients and $14 \%(208 / 1445)$ for those not treated (14\%, 208/1445). Thirty day mortality was $12 \%$ (19/156) versus $12 \%$ (169/1386), respectively, excluding unknown outcomes. New institutionalisation rates for eligible and discharged patients were 4\% (6/137) and $7 \%(81 / 1196)$, respectively. Length of stay was known for 1595 eligible patients and median (IOR) stays for treated and untreated patients were 9 (4-24) days and 12 (5-31) days, respectively. The numbers are too small to meaningfully stratify by further organisational or clinical features.

\section{DISCUSSION}

A number of centres have reported their local stroke thrombolysis rates, ranging from $1.6 \%$ to $18 \% .^{15-18}$ Several authors have attempted to model the number of potential patients suitable for thrombolysis from hospital and population based registers, again with large differences between studies, ranging from $0.4 \%{ }^{19}$ of patients benefiting from treatment to $8 \%$ in Cincinnati ${ }^{20}$ and $24 \%{ }^{21}$ in The Netherlands, suitable to be treated. This study however provides one of the first estimates at a national level of the provision of and need for thrombolysis services. It shows that about $14 \%$ of patients admitted to hospital with acute stroke are likely to be eligible for thrombolysis, and that only $10 \%$ of these patients actually receive it $(1.4 \%$ of the total stroke population). Provision of a daytime service alone without 
Table 2 Case mix and admission characteristics in relation to eligibility for, and if eligible the provision of, thrombolysis ( $\mathrm{n}=11262$ unless stated otherwise)

\begin{tabular}{|c|c|c|c|c|c|c|}
\hline & & Per cent & $\begin{array}{l}\text { Eligible } \\
\text { patients }\end{array}$ & Per cent & $\begin{array}{l}\text { Treated } \\
\text { patients }\end{array}$ & $\begin{array}{l}\text { p Value } \\
\text { for treatment* }\end{array}$ \\
\hline \multirow[t]{4}{*}{ Age (if not over 80 years) } & $<55$ & 23 & $181 / 804$ & 14 & $26 / 181$ & \multirow[t]{4}{*}{0.004} \\
\hline & $55-64$ & 24 & $312 / 1303$ & 13 & $39 / 312$ & \\
\hline & $65-74$ & 25 & $569 / 2299$ & 8 & $47 / 569$ & \\
\hline & $75-80$ & 25 & $543 / 2205$ & 9 & $48 / 543$ & \\
\hline \multirow[t]{2}{*}{ Sex } & Male & 18 & $937 / 5306$ & 11 & 99/937 & \multirow[t]{2}{*}{0.35} \\
\hline & Female & 11 & $668 / 5956$ & 9 & $61 / 668$ & \\
\hline \multirow{4}{*}{$\begin{array}{l}\text { Worst level of consciousness at time of } \\
\text { maximum severity within first week after } \\
\text { stroke (known for } 11261 \text { ) }\end{array}$} & $\begin{array}{l}\text { Unconscious (responds to pain only/no } \\
\text { response) }\end{array}$ & 10 & $143 / 1476$ & 10 & $14 / 143$ & \multirow[t]{4}{*}{0.82} \\
\hline & Semi-conscious (not fully rousable) & 12 & $104 / 859$ & 10 & $10 / 104$ & \\
\hline & Drowsy & 15 & $287 / 1959$ & 11 & $33 / 287$ & \\
\hline & Fully conscious & 15 & $1071 / 6967$ & 10 & $103 / 1071$ & \\
\hline \multirow{3}{*}{$\begin{array}{l}\text { Patient independent in everyday activities } \\
\text { before stroke (eg, Barthel 19-20, Rankin } \\
<3 \text { ) }\end{array}$} & Yes & 16 & 1388/8495 & 11 & $153 / 1388$ & \multirow{3}{*}{$\begin{array}{l}0.002 \\
\text { Yes vs No }\end{array}$} \\
\hline & No & 8 & $182 / 2364$ & 4 & $7 / 182$ & \\
\hline & Not known & 9 & $35 / 403$ & 0 & $0 / 35$ & \\
\hline \multirow{3}{*}{$\begin{array}{l}\text { Time of admission (known for } 10538 \text { who } \\
\text { were admitted after stroke) }\end{array}$} & Working hours (08:00-18:00) & 13 & $903 / 7070$ & 14 & $126 / 903$ & \multirow{3}{*}{$\begin{array}{l}<0.001 \\
\text { WH vs } 00 \mathrm{H}\end{array}$} \\
\hline & Out of hours & 13 & $446 / 3468$ & 5 & $24 / 446$ & \\
\hline & Already an inpatient & 44 & $256 / 587$ & 4 & $10 / 256$ & \\
\hline \multirow{3}{*}{$\begin{array}{l}\text { Ambulance clinicians' patient record on } \\
\text { file and FAST available }\end{array}$} & Yes & 18 & $433 / 2474$ & 21 & $90 / 433$ & \multirow[t]{3}{*}{$<0.001$ Yes vs no } \\
\hline & No & 12 & $717 / 6212$ & 7 & $51 / 717$ & \\
\hline & Not applicable & 18 & $455 / 2576$ & 4 & $19 / 455$ & \\
\hline \multirow{2}{*}{$\begin{array}{l}\text { Use of any lipid lowering treatment before } \\
\text { admission }\end{array}$} & Yes & 17 & $728 / 4255$ & 8 & $56 / 728$ & \multirow[t]{2}{*}{0.006} \\
\hline & No & 13 & $877 / 7007$ & 12 & $104 / 877$ & \\
\hline \multirow{3}{*}{$\begin{array}{l}\text { No of known comorbidities before } \\
\text { admission (range } 0-7 \text { as listed below) }\end{array}$} & 0 & 14 & $298 / 2133$ & 18 & $54 / 298$ & \multirow[t]{3}{*}{$<0.001$} \\
\hline & 1 or 2 & 13 & $826 / 6155$ & 9 & $74 / 826$ & \\
\hline & 3 or more & 16 & $481 / 2974$ & 7 & $32 / 481$ & \\
\hline \multirow[t]{2}{*}{ Atrial fibrillation } & Yes & 13 & $317 / 2462$ & 7 & $23 / 317$ & \multirow[t]{2}{*}{0.08} \\
\hline & No & 15 & $1288 / 8800$ & 11 & $137 / 1288$ & \\
\hline Previous stroke/TIA & Yes & 13 & $439 / 3260$ & 6 & $27 / 439$ & 0.001 \\
\hline & No & 15 & $1166 / 8002$ & 11 & $133 / 1166$ & \\
\hline Diabetes & Yes & 16 & $314 / 1963$ & 6 & $20 / 314$ & 0.016 \\
\hline & No & 14 & $1291 / 9299$ & 11 & $140 / 1291$ & \\
\hline Hyperlipidaemia (total cholesterol $>5$ & Yes & 17 & $484 / 2806$ & 9 & $44 / 484$ & 0.47 \\
\hline or $\mathrm{LDL}>3.0 \mathrm{mmol} / \mathrm{l}$ & No & 13 & $1121 / 8456$ & 10 & $116 / 1121$ & \\
\hline Hypertension (systolic $>140$ or & Yes & 14 & $893 / 6239$ & 8 & $75 / 893$ & 0.023 \\
\hline diastolic $>85$ ) & No & 14 & $712 / 5023$ & 12 & $85 / 712$ & \\
\hline Myocardial infarction or angina & Yes & 17 & $360 / 2166$ & 6 & $20 / 360$ & 0.001 \\
\hline & No & 14 & $1245 / 9096$ & 11 & $140 / 1245$ & \\
\hline Valvular heart disease (aortic or mitral & Yes & 17 & $67 / 395$ & 6 & $4 / 67$ & 0.40 \\
\hline valves) & No & 14 & $1538 / 10867$ & 10 & $156 / 1538$ & \\
\hline No of dysphasia, dysarthria, motor & 0 & 10 & $142 / 1477$ & 1 & $1 / 142$ & $<0.001$ \\
\hline deficits during the first $24 \mathrm{~h}$ & 1 & 13 & $503 / 3938$ & 4 & $22 / 503$ & \\
\hline & 2 & 17 & $672 / 4002$ & 13 & $89 / 672$ & \\
\hline & 3 & 16 & $288 / 1845$ & 17 & $48 / 288$ & \\
\hline Dysphasia & Yes & 15 & $676 / 4425$ & 14 & $97 / 676$ & $<0.001$ \\
\hline & No & 15 & $829 / 5693$ & 7 & $61 / 829$ & Yes vs no \\
\hline & Not known & 9 & $100 / 1144$ & 2 & $2 / 100$ & \\
\hline Dysarthria & Yes & 16 & $723 / 4384$ & 13 & $96 / 723$ & 0.001 \\
\hline & No & 14 & $750 / 5373$ & 8 & $60 / 750$ & Yes vs no \\
\hline & Not known & 9 & $132 / 1505$ & 3 & $4 / 132$ & \\
\hline Motor deficits & Yes & 15 & $1312 / 8668$ & 12 & $151 / 1312$ & $<0.001$ \\
\hline & No & 12 & $249 / 2071$ & 4 & $9 / 249$ & Yes vs no \\
\hline & Not known & 8 & $44 / 523$ & - & $0 / 44$ & \\
\hline Current smoker & Yes & 20 & $369 / 1850$ & 10 & $37 / 369$ & 0.99 \\
\hline & No & 13 & $1236 / 9412$ & 10 & $123 / 1236$ & \\
\hline Alcohol excess (no of units per week $>21$ & Yes & 18 & $120 / 683$ & 10 & $12 / 120$ & 0.99 \\
\hline for females, $>28$ males & No & 14 & $1485 / 10579$ & 10 & $148 / 1485$ & \\
\hline
\end{tabular}

*Fisher's exact test was used, except for where the Mann-Whitney test was used with age in years and where $\chi^{2}$ test was used for worst level of consciousness, No of comorbidiy groups and No of known symptoms limiting physical function.

FAST, Face, Arm, Speech Test; LDL, low density lipoprotein; TIA, transient ischaemic attack.

access to night-time acute stroke care will result in a significant number of patients being denied best quality care. Twenty-four hour services are therefore essential. These data show that a major step change in stroke care is feasible by improved delivery of care. Provision of high quality acute stroke services, accessible to the whole population rather than the current 
patchy delivery of care, should be able to increase the number of patients thrombolysed 10-fold. The most important actions, within current European licensing, to increase the proportion of patients eligible for treatment, will be to reduce the delay between onset of symptoms and arrival in hospital and to ensure that all hospitals treating acute stroke patients should have the skills and resources to offer thrombolysis at all times. This will require both increased public awareness and better professional management in the prehospital phase. It has been shown that where the FAST ${ }^{22}$ is being used patients are more likely to be thrombolysed but this may simply reflect services organising themselves to deliver care effectively. An Australian randomised controlled trial has shown that a prehospital protocol increases access to treatment ${ }^{23}$ and this has also been demonstrated in the USA. $^{24}$ Improving public awareness of the symptoms of stroke and how to respond when they happen is being addressed in England with a major advertising campaign funded by the Department of Health and ongoing awareness raising by the Stroke Association, although the efficacy of such campaigns remains unproven. A recent study reported a significant increase in the proportion of patients thrombolysed admitted to academic medical centres in the USA between 2001 and 2004 from $14 \%$ of those admitted within $2 \mathrm{~h}$ of symptom onset to $37.5 \%$, but with no significant increase in the proportion arriving within $2 \mathrm{~h}(37-38 \%){ }^{25}$

Offering tPA up to $4.5 \mathrm{~h}$ is only going to marginally increase the rates of thrombolysis and because of the high number needed to treat between 3 and $4.5 h^{2}$ this change in practice will have a small impact on outcomes at a population level. The message that treatment is still available up to $4.5 \mathrm{~h}$ may actually make outcomes worse if there is a mistaken belief that the patients and professionals can afford to take their time and therefore not treat each case as an emergency. Approximately $40 \%$ of patients who are in hospital within $3 \mathrm{~h}$ of stroke are excluded from thrombolysis when delivered according to the European license because they are over the age of 80 years. The trial currently being funded by the MRC (IST 3) evaluating among other things whether the drug can be given safely and effectively to older patients is therefore of major importance and if shown would have the greatest impact on the proportion of patients eligible for thrombolysis. If the ongoing trials of treating patients with mismatch on diffusion/perfusion scanning show positive results, then again a significant increase in the number of patients eligible for treatment would be expected as some of the patients with 'wake up' strokes and those with unknown time of onset could be treated.

These data show marked differences between centres in the proportion of patients meeting the NINDS eligibility criteria but this is consistent with random variation between hospitals with relatively small sample sizes. That these data do not show significant differences in outcome between those treated and not treated with thrombolysis is likely to reflect the very small numbers of patients that were treated. These are observational data, not a randomised controlled trial, and differences may also reflect any local level selection biases for thrombolysis in eligible patients due to their clinical condition. The Cochrane review ${ }^{1}$ shows that treatment is worthwhile and the SITS-MOST audit ${ }^{3}$ suggests that the treatment can be delivered safely in routine clinical practice although it must be acknowledged that this database may not represent a complete record of all thrombolysis treatments given and may therefore have some bias. What we have shown that is very concerning is that some centres appear to be delivering thrombolysis without the highest quality stroke service in place to support the treatment. Thrombolysis is only one relatively small component of acute stroke care and should only be provided when a high quality environment is established. NICE guidance ${ }^{1112}$ states that alteplase should only be administered within a well organised stroke service with staff trained in delivering thrombolysis and in monitoring for any associated complications, care up to level 1 and level 2 nursing staff trained in acute stroke and thrombolysis immediate access to imaging. Additionally, many centres providing thrombolysis are only treating very small numbers of patients. Data from the German Stroke Registers Study Group ${ }^{26}$ have shown that outcomes are better from units performing at least 15 procedures per year. This would suggest that reorganisation of care should concentrate acute stroke care in a smaller number of larger specialist centres. The Stroke Organisational audit in $2009^{27}$ showed that, of 210 sites providing acute care, $138(66 \%)$ claimed to have thrombolysis available on site, but only $47(22 \%$ of all acute sites) had administered the treatment to 15 or more patients in the previous year. These numbers are something of an improvement on the organisational audit in $2008^{28}$ which showed that, of 213 sites providing acute care, 91 (43\%) claimed to have thrombolysis available on site but only $22(10 \%$ of all acute sites) had administered treatment to 15 or more patients in the previous year. One-third of patients (446/1605=28\%) eligible for thrombolysis were admitted outside normal working hours (08:00 through 18:00 h) and these data show that $24 \mathrm{~h}$, 7 days a week acute stroke care is essential.

The strengths of this study are that it involves all acute stroke providers in England, Wales and Northern Ireland and uses a well established and accepted methodology ${ }^{29}$ that has been used by local hospitals, strategic health authorities and government to develop services. The potential weaknesses are that the number of patients included from each centre is relatively small and the total number of patients treated with alteplase within the sample is very small. Data are self-reported and may therefore be open to bias, both through patient selection and inaccuracy in reporting. We do not believe that this is a major factor, particularly for the data items used in this analysis, given the good inter-rater reliability. Data were not collected that enabled complete certainty about the proportion of patients that were eligible for thrombolysis but the numbers in clinical practice that are excluded because of these factors such as hypertension, recent bleeding and use of anticoagulants are relatively small. In the 2006 audit, $7 \%$ of patients were admitted on warfarin, $78 \%$ were independent prior to admission (Barthel 19 or 20 or a Rankin of $<3$ ) with only 7\% (from the 2001-2002 audit) being so severely impaired prior to the stroke as to preclude the use of thrombolysis, with a Barthel of less than 10. There is also some uncertainty about the time from onset to admission due to rounding of times to the nearest hour, and there are some patients for whom the admission times were not known. Thrombolysis is an important component of stroke care that is currently applicable to about $14 \%$ of the stroke population. In England, Wales and Northern Ireland, only 10\% of eligible patients are currently receiving the treatment. Extending the thrombolysis time window from 3 to $4.5 \mathrm{~h}$ will have a minimal effect on the number of patients treated. The major factors that might increase the number will be if it can be shown that the drug can be given safely to patients over the age of 80 years and public awareness increases so that a greater proportion of patients arrive within the hospital in time to be treated.

Acknowledgements We are grateful to all of the people who completed the data in all the hospitals in England, Wales and Northern Ireland. 
Funding The Healthcare Commission and HQIP funded the National Sentinel Audit of Stroke.

Competing interests None.

Provenance and peer review Not commissioned; externally peer reviewed.

\section{REFERENCES}

1. Wardlaw JM, del Zoppo G, Yamaguchi T. Thrombolysis for acute ischaemic stroke. Cochrane Database Syst Rev 2000;2:CD000213. Update in: Cochrane Database Syst Rev 2003;3:CD000213.

2. Hacke W, Kaste M, Bluhmki E, et al. Toni D for the ECASS investigators. Thrombolysis with alteplase 3 to 4.5 hours after acute ischaemic stroke. $N$ Engl J Med 2008;359:1317-29.

3. Wahlgren N, Ahmed N, Dávalos A, et al. SITS-MOST investigators. Thrombolysis with alteplase for acute ischaemic stroke in the Safe Implementation of Thrombolysis in Stroke-Monitoring Study (SITS-MOST): an observational study. Lancet 2007:369:275-82.

4. Katzan IL, Furlan AJ, Lloyd LE, et al. Use of tissue-type plasminogen activator for acute ischaemic stroke: the Cleveland area experience. JAMA 2000:282:1151-8.

5. Heuschmann PU, Berger K Misselwitz B, Hermanek P. For the German Stroke Registers Study Group. Frequency of thrombolytic therapy in patients with acute ischaemic stroke and the risk of in-hospital mortality. Stroke 2003:34:1106-13.

6. Bray JE, Coughlan K, Bladin C. Thrombolysis therapy for acute ischaemic stroke: successful implementation in an Australian tertiary hospital. Intern Med J 2006:36:483-8.

7. Steiner MM, Brainin M; Austrian Stroke Registry for Acute Stroke Units. The quality of acute stroke units on a nation-wide level: the Austrian Stroke Registry for acute stroke units. Eur J Neurol 2003;10:353-60.

8. Royal College of Physicians. National Sentinel Stroke Audit. Clinical audit. London: Royal College of Physicians, 2006. http://www.rcplondon.ac.uk/clinical-standards/ ceeu/Current-work/Documents/Public\%20organisational\%20report2008.pdf.

9. Walters MR, Muir KW, Harbison J, et al. Intravenous thrombolysis for acute ischaemic stroke: preliminary experience with recombinant tissue plasminogen activator in the UK. Cerebrovasc Dis 2005;20:438-42.

10. Department of Health. National Stroke Strategy. London: Department of Health, 2007. http://www.dh.gov.uk/publications.

11. Anon. NICE Guideline on Diagnosis and Initial Management of Acute Stroke and TIA. 2008. http://www.nice.org.uk/nicemedia/pdf/CG68FullGuideline.pdf.

12. Anon. NICE Technology Appraisal Alteplase TA122. 2007. http://www.nice.org.uk/ Guidance/TA122.

13. Royal College of Physicians. National sentinel stroke audit. Clinical audit. London: Royal College of Physicians, 2008. http://www.rcplondon.ac.uk/clinical-standards/ ceeu/Current-work/Documents/.
14. The National Institute of Neurological Disorders and Stroke rt-PA Stroke Study Group. Tissue plasminogen activator for acute ischaemic stroke. N Engl J Med 1995;333:1581-7.

15. Reed SD, Cramer SC, Blough DK, et al. Treatment with tissue plasminogen activato and inpatient mortality rates for patients with ischaemic stroke treated in community hospitals. Stroke 2001:32:1832-40.

16. Johnston SC, Fung LH, Gillum LA, et al. Utilization of intravenous tissue-type plasminogen activator for ischaemic stroke at academic medical centres; the influence of ethnicity. Stroke 2001:32:1061-8.

17. Barber PA, Zhang J, Demchuk AM, et al. Why are stroke patients excluded from TPA therapy? An analysis of patient eligibility. Neurology 2001;56:1015-20.

18. Demaerschalk BM, Bobrow BJ, Paulsen M. Development of a metropolitan matrix of primary stroke centres: the phoenix experience. Stroke 2008;39:1246-53.

19. Jørgensen HS, Nakayama H, Kammersgaard LP, et al. Predicted impact of intravenous thrombolysis on prognosis of general population of stroke patients: simulation model. BMJ 1999;319:288-9.

20. Kleindorfer D, Kissela B, Schneider A, et al. Neuroscience Institute. Eligibility for recombinant tissue plasminogen activator in acute ischaemic stroke: a population based study. Stroke 2004;35:e27-9.

21. Boode B, Welzen V. Franke C, et al. Estimating the number of stroke patients eligible for thrombolytic therapy if delay could be avoided. Cerebrovasc Dis 2007:23:294-8.

22. Ford GA, Nor AM, McAllister $\mathrm{C}$, et al. Agreement between ambulance paramedic and physician-recorded neurological signs with Face Arm Speech Test (FAST) in acute stroke patients. Stroke 2004;35:1355-9.

23. Quain DA, Parsons MW, Loudfoot AR, et al. Improving access to acute stroke therapies: a controlled trial of organised pre-hospital and emergency care. Med J Aust 2008:189:429-33.

24. Wojner-Alexandrov AW, Alexandrov AV, Rodriguez D, et al. Houston paramedic and emergency stroke treatment and outcomes study (HoPSTO). Stroke 2005:36:1512-18.

25. Lichtman JH, Watanabe E, Allen NB, et al. Hospital arrival time and intravenous t-PA use in US Academic Medical Centers, 2001-2004. Stroke 2009:40:3845-50.

26. Heuschmann PU, Kolominsky-Rabas PI, Roether J, et al. for the German Stroke Registers Study Group. Predictors of in-hospital mortality in patients with acute ischaemic stroke treated with thrombolytic therapy. JAMA 2004;292:1831-8.

27. Intercollegiate Stroke Working Party. National Sentinel Audit of Stroke Organisation of Stroke Care in England, Wales and Northern Ireland, 2009 http://www.rcplondon.ac.uk/stroke.

28. Intercollegiate Stroke Working Party. National Sentinel Audit of Stroke Organisation of Stroke Care in England, Wales and Northern Ireland. 2008. http://www.rcplondon.ac.uk/stroke.

29. Rudd AG, Hoffman A, Irwin P, et al. Stroke units: research and reality. Results from the National Sentinel Audit of Stroke. Oual Saf Health Care 2005;14:7-12. 